UNDERGROUND MINING ENGINEERING 36 (2020) 29-48 UDK 62

\title{
FUZZY LOGIC MODEL FOR STABILITY ASSESSMENT OF UNDERGROUND FACILITIES
}

\author{
Luka Crnogorac ${ }^{1}$, Rade Tokalić ${ }^{1}$, Kemal Gutić ${ }^{2}$, Saša Jovanović ${ }^{3}$, Duško \\ Đukanović $^{4}$
}

Received: April 15, 2020

Accepted: June 8, 2020

\begin{abstract}
A proper assessment of the stability leads to proactive decision making for the method of construction, the shape and size of the cross-section of the facility and the adequate support. The stability is directly dependent on the physical, mechanical and technical characteristics of the rock mass. The traditional assessment-based approach and the classification of stability of underground facilities is based on both experience and experiments with previously constructed facilities. To ease the process for the early phase of design, there was a need for the development of a mathematical model for assessment of the stability. Ambiguity in mining engineering, directs the development of the model using a fuzzy logic system and fuzzy "if-then" rules. The model was developed based on very scarce input data that is most often the only data available during the design stage. Fuzzy model results have shown, through the random selection of input data in the model, that in $70 \%$ of cases, there is high numerical congruence with the traditional method for determination of coefficient of stability S; and in $90 \%$ of cases, there is also congruence in accordance with the traditional approach to the classification of underground facilities based on the stability assessment.
\end{abstract}

Keywords: underground construction; stability assessment; fuzzy logic;

\section{INTRODUCTION}

The increasing need for the global construction of underground facilities. is due to the rapid expansion of urban zones -e.g. underground passages, parking spaces, underground tunnels for road traffic, the development of a network of underground city railways, metros, a larger number of communal tunnels, as well as underground mining roadways and facilities. These underground facilities that are necessary for the utilization

\footnotetext{
${ }^{1}$ University of Belgrade - Faculty of Mining and Geology

${ }^{2}$ University of Tuzla - Faculty of Mining, Geology and Civil Engineering, B\&H

${ }^{3}$ University of Priština - Kosovska Mitrovica, Faculty of Technical Sciences, Serbia

${ }^{4}$ University of Belgrade - Technical Faculty in Bor, Serbia

Emails: luka.crnogorac@rgf.bg.ac.rs; rade.tokalic@rgf.bg.ac.rs; kemal.gutic@untz.ba; sasa.m.jovanovic@pr.ac.rs; ddjukanovic@tf.bor.ac.rs
} 
of mineral resource, however, lie deep within the earth's depths, due to a long exploitation period of mineral resource deposits within surface mining. Furthermore, the high standards set within the field of environmental protection either do not allow disturbances of the terrain or require the re-cultivation of the degraded terrain (created in the midst of mining activities). These have, consequently, led to an increase in ore prices.

Moreover, the underground construction of these facilities presents a very complex problem, primarily because of the working environment (e.g. rock mass) which consists of rocks with different physical and chemical compositions and sometimes with great structural differences in very small areas. Its physical and chemical composition, as well as genesis, mineral composition, structural, texture, physical and hydrological characteristics and tectonicism, thus influence the physical, mechanical and technical characteristics of the rock mass. This leads to the conclusion that, with the application of fuzzy sets, the parameters of the rock mass can be classified in much more detail.

Underground constructions must be stable and to ensure this stability, it is necessary to install a support system. The shape and dimensions of underground facilities are conditioned by the characteristics of the rock mass, as well as the shape and dimensions of the support system -which depend on the stability of the underground space. Also, construction method of underground facility is of importance to the stability, for example methods that consist of drill and blast works have more influence on contours of the underground facilities than mechanized construction methods (with road headers or tunnel boring machines). Reason is that blasting has a negative effect in terms of formation of the oscillations of the rock mass particles, those oscillations are manifested and felt as a shock (Lutovac et al., 2018) which has an impact on the contours of the underground facilities.

The traditional assessment-based methods used to determine the stability of underground facilities are based on the experience gained from previously-constructed underground facilities, while the mathematical model for predicting the stability of underground facilities, is almost non-existent. This experience can then be used to define linguistic variables that would be brought into the fuzzy logic relationship through appropriate membership functions.

The fuzzy model, used for assessing the stability of underground facilities, would facilitate the construction of these facilities as it provides better perspective on scarce data. With the implementation of the fuzzy model, comes the need for a properly-selected support system and an accurate dimension of the cross-section of these underground facilities. 


\section{TRADITIONAL APPROACH TO STABILITY ASSESSMENT}

The selection of an appropriate support system is one of the most complex tasks in the process of underground construction since the support systems serve to stabilize the underground facilities during the process of production and its period of exploitation. Furthermore, in the design phase, there is lack of data on the rock mass (through which the underground facilities are constructed).

The type of support system depends partially on the shape and dimensions of the underground facilities as well as on the value of the underground pressure and the estimated stability of the contours of the underground facilities. It is necessary to adopt an adequate support system that can resist all the loads and will preserve the designed shape and dimensions of the underground facility (Kobliška, 1973) so that, ultimately, the shape and dimensions are directly dependent on the type of support system chosen and its level of stability.

Stability is very important in terms of its construction and exploitation. There is the notion that stability is associated with a particular feature of rock mass which serves to preserve the shape and dimensions of the constructed facility, i.e. the deformations of the rock mass surrounding the underground facility do not go beyond the area of the elasticity of the material (Jovanović, 1990). The rock mass (i.e. working environment) with this feature is considered stable and therefore does not often require a support system. Some rock masses however are easily deformed, resulting in cracks in, and the eventual collapse of, the material; and in such cases these underground facilities require the installation of support systems in order to maintain stability.

The possibility of a collapse in the contour of the underground facilities is related to the petrographic composition and strength of the rock mass, the macrostructure, the density, the orientation of the cracks in the rock mass, the depth of the facility, the size of the cross-section of the facility, the construction technology, etc. Stability also depends on material flow characteristics as well as on the atmospheric influences that prevail in underground facilities - e.g. air, humidity, temperature changes, etc. (Jovanović and Zeković, 1992). The research, that is necessary for fully understanding the values of all factors influencing the stability of underground facilities, would be very expensive and time consuming. The solution is, therefore, to rely on the information gathered through the monitoring of underground objects' behavioral patterns within different working conditions (Jovanović, 1994).

The stability of the rock mass is determined and classified by different criteria. The most commonly-used criteria for assessing stability (Vidanović and Tokalić, 2011) are:

The general criterion of stability based on the ratio of the pressure values and the carrying capacity of the rock mass, 


$$
k \cdot \gamma \cdot H \leq \xi \cdot n \cdot R
$$

where:

$\gamma$ - unit weight of overburden; $\mathrm{k}$ - stress concentration coefficient; $\mathrm{H}$ - object depth; $\xi-$ flow coefficient; $\mathrm{n}$ - coefficient of damage to the rock mass and $\mathrm{R}$ - uniaxial compressive strength of rock mass.

The stability criterion, according to Ju. Z. Zaslavsky, representing the ratio of hydrostatic load and uniaxial compressive strength of the rock mass

$$
S=\frac{\gamma \cdot H}{R}
$$

where:

$\gamma$ - unit weight of overburden; $\mathrm{H}$ - object depth and $\mathrm{R}$ - uniaxial compressive strength of rock mass.

The criterion of stability by F. Mour

$$
S=C \cdot \frac{(1+\sin \varphi)^{2}}{\gamma \cdot H \cdot(1-\sin \varphi)}
$$

where:

$\mathrm{C}$ - cohesion; $\gamma$ - unit weight of overburden; $\mathrm{H}$ - object depth and $\varphi$ - angle of internal friction.

All above mentioned criteria are applicable in estimating the stability of the rock mass when the underground facility is constructed in solid and weak (fragile) rock mass. On the other side, for stability assessment of rock mass in case of underground construction in rock mass with the plastic behavior criteria for stability assessment are a bit different (Jovanović, 1990). These criteria are shown in eq. 4 and eq. 5.

The general criterion of stability based on the ratio of the pressure values and the carrying capacity of the rock mass with plastic behavior:

$$
k \cdot \gamma \cdot H \leq \xi \cdot n \cdot R \cdot K_{s}
$$

where:

$\gamma$ - unit weight of overburden; $\mathrm{k}$ - stress concentration coefficient; $\mathrm{H}$ - object depth; $\xi-$ flow coefficient; $\mathrm{n}$ - coefficient of damage to the rock mass and $\mathrm{R}$ - uniaxial compressive 
strength of rock mass and Ks - a coefficient characterized by an increase in the stability of the rock mass capable of plastic deformation (see eq. 4.1.).

$$
K_{S}=\frac{P^{\frac{\alpha}{2}}-1}{\sin \varphi},
$$

where:

$\mathrm{P}$ - an indicator of the plastic behavior of the rock mass; $\varphi$ - angle of internal friction and $\alpha$ is represented with eq. 4.2.

$$
\alpha=\frac{2 \sin \varphi}{1-\sin \varphi}
$$

where:

$\varphi$ - angle of internal friction.

According to Ju. Z. Zaslavsky, floor of horizontal underground facility is stable if the heaving doesn't have larger value than $200 \mathrm{~mm}$. This requirement is met when:

$$
2 a=A \cdot \frac{R}{\gamma \cdot H^{\prime}}
$$

where:

$2 \mathrm{a}$ - width of the underground facility; $\gamma$ - unit weight of overburden; $\mathrm{H}$ - object depth and $\mathrm{R}$ - uniaxial compressive strength of rock mass and $\mathrm{A}$ - coefficient which takes into account the position of the underground facility in relation to the mineral deposit $(A=1,6$ for transversal hallways, $\mathrm{A}=1,22$ for all other positions of hallways).

In this paper, the stability criterion, according to Ju. Z. Zaslavsky, will be used as the control parameter for the fuzzy model -which is presented more explicitly in Section 5. Zaslavsky conducted experimental research and classified stability with the value of coefficient of stability $\mathrm{S}$ (while also recommending type of a support system to be used).

Generally, in underground mines most common types of support are steel circular, steel arched, timber trapezoid and steel trapezoid support, with other support types least frequently used. Researches showed, in order to overcome existing problems related to development of underground roadways and maintaining their stability, could be found 
in implementation of active roof support (lightweight support) (Milisavljević et al., 2016).

\section{LITERATURE SURVEY}

The widespread implementation of fuzzy logic in engineering is a result of approximate determination rather than the reliance on more precise data (which is generally absent from engineering-related problem-solving approaches, especially at the design stage). Given that man's thought process/pattern is governed by nature, fuzzy logic, therefore, serves as a familiar tool. The creator of fuzzy logic, L. Zadeh, concluded, in his analysis of complex systems, that as the complexity of the system increases, our possibilities of precise observation and behaviour of the system, decrease (Zadeh, 1964; Kričak et al., 2015).

As part of the solution process in mining engineering, fuzzy logic, as in other engineering branches, has found its purpose and application. Thus, the fuzzy logic approach was applied to the classification of rock mass (Aydin, 2004; Hamidi et al., 2010; He et al., 2014), serving to assess the stability of the slopes (Daftaribeshelia et al., 2011), the predicted rate of penetration in rotary drilling (Kričak et al., 2015), tunnel construction (Tréfová et al., 2011) the use of rational technology for the construction of underground facilities (Tokalić et al., 2013), the management process in mineral processing (Miljanović, 2008) and production planning in bauxite mines (Vujić and Miljanović, 2013). Fuzzy programming model, containing fuzzy measures of costs and ore reserves was developed to evaluate different design alternatives in order to select underground mine development system (Jovanović et al., 2014). Fuzzy logic combined with multiplecriteria decision-making (AHP method) was implemented in a model for underground mining method selection, and it linked problems in mining industry with fuzzy logic and multi-criteria decision-making, finding that fuzzy AHP is extremely useful technique in mining industry (Bajić et al., 2020).

As previously mentioned, set theory and fuzzy logic have been integral tools for resolving mining engineering problems. In fact, the fuzzy set theory and fuzzy logic approach could serve as a solution to one of the largest underground mining engineering problems, stability assessment.

\section{$4 \quad$ FUZZY LOGIC}

Fuzzy logic, unlike classic logic (in which the determinants have clearly defined values such as "true" or "false") provides the possibility that the values of the determinants belong to a series of "true" to "false" values (Vujić and Miljanović, 2013). Fuzzy set theory is knowledge representation via fuzzy set rules. Fuzzy set theory offers a systematic calculus to deal with information and perform numerical calculations through linguistic designation (which are determined by membership functions) (Jang et al., 
1997). If $X$ is a collection of objects denoted generically by $x$, then fuzzy set $A$ in $X$ is defined as a set of ordered pairs:

$$
A=\left\{\left(x, \mu_{A}(x)\right) \text { I } x=X\right\}
$$

where:

$\mu_{A}(x)-$ is the membership function for the fuzzy set A.

The membership function maps each element of $X$ to a membership value from 0 to 1 . In Figure 1., typical membership functions of linguistic values "young“, "middle-aged" and ,"old" can be seen, where X represents age.

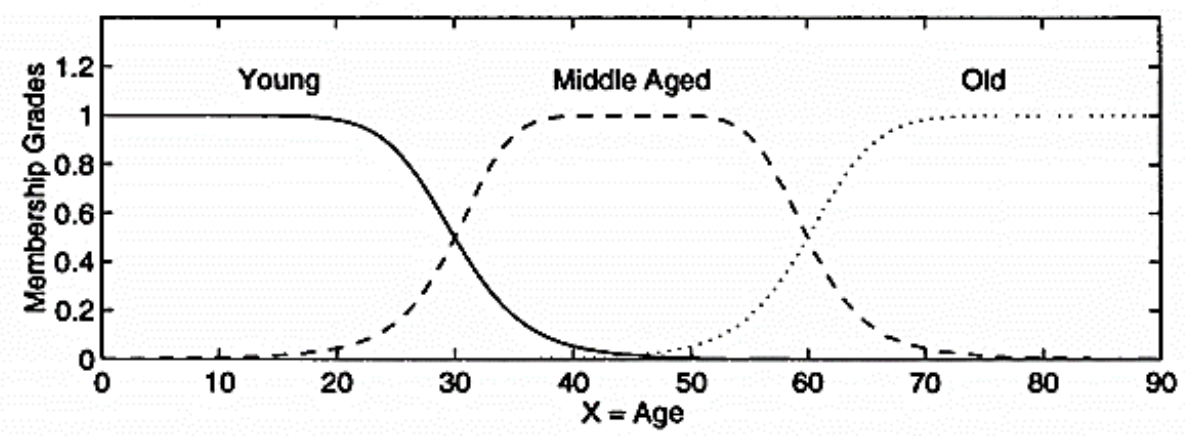

Figure 1 Example of typical membership functions (J.R. Jang et al., 1997)

Membership functions can be one dimensional (or greater) and come in various shapes -e.g. triangular, trapezoid, Gaussian, generalized bell, sigmoidal, etc. One of the most common shapes, given its simplicity, is triangular. In one model, different membership functions can be used while the model shown in this paper relied on a combination of Trapezoid and Gaussian-shaped membership functions.

A Trapezoid membership function is specified by four parameters $\{a, b, c, d\}$ as follows:

$$
\operatorname{trapezoid}(x ; a, b, c, d)=\begin{aligned}
0, & x \leq a . \\
\frac{x-a}{b-a}, & a \leq x \leq b . \\
1, & b \leq x \leq c . \\
\frac{d-x}{d-c}, & c \leq x \leq d . \\
0, & x \geq d .
\end{aligned}
$$


The parameters $\{\mathrm{a}, \mathrm{b}, \mathrm{c}, \mathrm{d}\}$ (with $\mathrm{a}<\mathrm{b} \leq \mathrm{c}<\mathrm{d}$ ) determine the $\mathrm{x}$ coordinates of the four corners of the underlying Trapezoid membership function. Figure 2. illustrates a Trapezoid membership function defined by a trapezoid $(x ; 10,20,60,95)$.

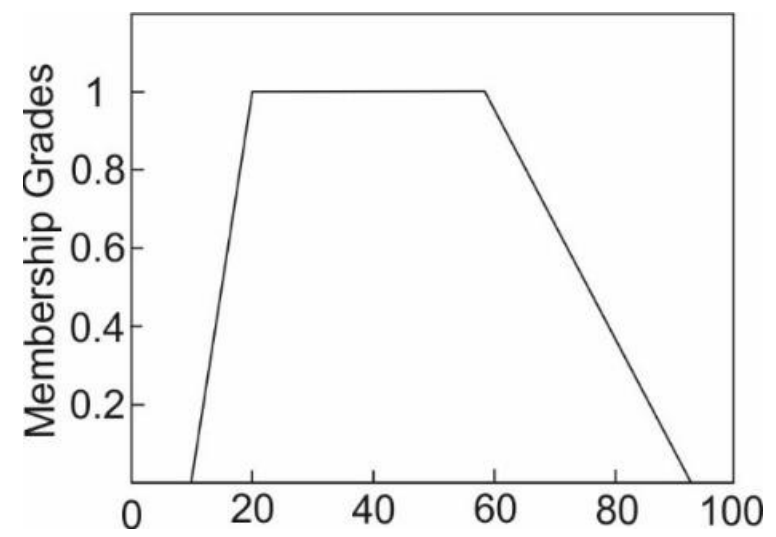

Figure 2 Illustration of a Trapezoid membership function (x; 10, 20, 60, 95)

A Gaussian membership function is specified by two parameters $\{\mathrm{c}, \sigma\}$ :

$$
\operatorname{gaussian}(x ; c, \sigma)=e^{-\frac{1}{2}\left(\frac{x-c}{\sigma}\right)^{2}},
$$

A Gaussian membership function is determined completely by $\mathrm{c}$ and $\sigma ; \mathrm{c}$ represents the membership function centre and $\sigma$ determines the width of membership function.

Fuzzy logic designer application (in Matlab R2015a) has made it possible to transform parameters of, e.g. triangular membership function, into other membership function shape. It can thus be concluded that the type (shape) of membership functions can be easily modified and the results it yields can be seen in the surface viewer.

Every fuzzy model consists of fuzzy "if-then" rules that describe complex systems by relating input and output parameters through the use of linguistic variables. A fuzzy ifthen rule assumes the form "if $\mathrm{x}$ is A then $\mathrm{y}$ is B," where A and B are linguistic values defined by fuzzy sets on universes of discourse $\mathrm{X}$ and $\mathrm{Y}$, respectively. Often " $\mathrm{x}$ is A" is called the antecedent or premise, while " $\mathrm{y}$ is B" is called the consequence or conclusion. An example of one fuzzy rule taken from the model for stability assessment is "If (uniaxial compressive strength is high) and (object depth is very high) and (unit weight is very high) then (coefficient of stability is medium)."

The fuzzy inference system (FIS) is a process of forming an input fuzzy set map to an output fuzzy set via fuzzy logic. There are several fuzzy inference systems in use, such as Mamdani, Takagi-Sugeno-Kang and Tsukamoto. The Mamdani algorithm was one of the first control systems developed on the fuzzy set theory. The Mamdani fuzzy interface 
system was proposed for the control of steam engines and boilers by a set of linguistic control-based rules. These control rules are based on the experience gained by human operators.

The general "if-then" rules structure of The Mamdani algorithm is given by the following equation:

$$
\text { If } x_{1} \text { is } A_{i 1} \text { and } x_{2} \text { is } A_{i 2} \ldots \text { and } x_{r} \text { is } A_{\text {ir }} \text { than } y \text { is } B_{i}(\text { for } i=1,2, \ldots, k) \text {, }
$$

where:

$\mathrm{k}$ - number of rules; $\mathrm{xi}$ - input variables; Air and $\mathrm{Bi}$ - linguistic terms and $\mathrm{y}$ - output variables.

The final step in the fuzzy model process is defuzzification. Defuzzification is a process where input is a fuzzy set and output from the process is a crisp number. The most widely-used defuzzification method is centroid of area (COA) or centre of gravity, because all of its activated membership functions of the conclusions (i.e. all active rules) take part in the defuzzification process.

\section{FUZZY MODEL FOR STABILITY ASSESSMENT OF UNDERGROUND FACILITIES}

The fuzzy model, used for estimating the stability of underground facilities in this paper, will be based on input parameters from the equation (i.e. Eq. 2) -which was originally proposed by Ju. Z. Zaslavsky (who also classified rock mass by stability -which is shown in table 2). The model was made using the Mamdani algorithm (Mamdani and Assilian, 1975 ) in the MATLAB fuzzy logic toolbox.

The model consists of three input variables and one output variable -all of which are linguistically described and defined by membership functions and numerical parameters.

\subsection{Variables}

The input variables relate to the uniaxial compressive strength of the rock mass, the depth of the object and the unit weight of overburden while the output variable is the coefficient of stability. Membership functions of all variables are Trapezoid or Gaussian shaped, since the triangular membership functions failed to yield expected results during the modelling process (in terms of stability classification); one explanation for this is that triangular membership functions leave a significant amount of, or cover too much, undefined area on the graph which can yield poor results from an engineering point of view. It was thus determined that a combination of Trapezoid and Gaussian-shaped membership functions yield the best results. 
Table 1 shows the variables with their extents, linguistic values and parameters.

Table 1 Input and output variables with their characteristics

\begin{tabular}{|c|c|c|c|c|}
\hline Variable & Linguistic variables & Extent & Linguistic value & $\begin{array}{c}\text { Parameter }{ }^{5} \text { and type of } \\
\text { membership function (MF) }\end{array}$ \\
\hline \multirow[t]{16}{*}{ Input } & \multirow{5}{*}{$\begin{array}{l}\text { Uniaxial compressive strength } \\
\text { of the rock mass (MPa) }\end{array}$} & \multirow[t]{5}{*}[0-150]{} & Very low (VL) & {$\left[\begin{array}{llll}0 & 0 & 25 & 50\end{array}\right]-$ T MF } \\
\hline & & & Low (L) & [10.62 50] - G MF \\
\hline & & & Medium (M) & [10.62 75] - G MF \\
\hline & & & High $(\mathrm{H})$ & [10.62 100] - G MF \\
\hline & & & Very high $(\mathrm{VH})$ & {$\left[\begin{array}{lllll}100 & 125 & 150 & 150\end{array}\right]-$ T MF } \\
\hline & \multirow[t]{5}{*}{ Object depth (m) } & \multirow{5}{*}{$\begin{array}{c}{[0-} \\
1200]\end{array}$} & Very low (VL) & [0 0200 400] - T MF \\
\hline & & & Low $(\mathrm{L})$ & [84.93 400] - G MF \\
\hline & & & Medium (M) & [84.93 600] - G MF \\
\hline & & & High $(\mathrm{H})$ & [84.93 800] - G MF \\
\hline & & & Very high $(\mathrm{VH})$ & {$\left[\begin{array}{llllll}800 & 1000 & 1200 & 1200\end{array}\right]-\mathrm{T}$ MF } \\
\hline & \multirow{6}{*}{$\begin{array}{l}\text { Unit weight of overburden } \\
\qquad\left(\mathrm{MN} / \mathrm{m}^{3}\right)\end{array}$} & \multirow{6}{*}{$\begin{array}{c}{[0-} \\
0.0375]\end{array}$} & Very low (VL) & {$\left[\begin{array}{llllll}0 & 0 & 0.0075 & 0.01125\end{array}\right]-\mathrm{T}$ MF } \\
\hline & & & Low $(\mathrm{L})$ & [0.002654 0.0125] - G MF \\
\hline & & & Medium (M) & [0.002654 0.01875] - G MF \\
\hline & & & High $(\mathrm{H})$ & [0.002654 0.025] - G MF \\
\hline & & & Very high (VH) & {$\left[\begin{array}{llllll}0.025 & 0.03 & 0.0375 & 0.0375\end{array}\right]$ - } \\
\hline & & & & T MF \\
\hline \multirow[t]{3}{*}{ Output } & \multirow[t]{3}{*}{ Coefficient of stability } & \multirow[t]{3}{*}[0-0.65]{} & High (stable) & {$\left[\begin{array}{lllll}0 & 0 & 0.25 & 0.3\end{array}\right]-\mathrm{T} \mathrm{MF}$} \\
\hline & & & $\begin{array}{c}\text { Medium } \\
\text { (medium stable) }\end{array}$ & {$\left[\begin{array}{lllll}0.25 & 0.3 & 0.4 & 0.45\end{array}\right]$ - T MF } \\
\hline & & & Low (unstable) & {$\left[\begin{array}{llll}0.4 & 0.45 & 0.65 & 0.65\end{array}\right]-\mathrm{T}$ MF } \\
\hline
\end{tabular}

\subsubsection{Uniaxial compressive strength of the rock mass}

The Uniaxial compressive strength of the rock mass, with a range from 0 to $150 \mathrm{MPa}$, is divided into five groups with the linguistic variables: very low (VL), low (L), medium $(\mathrm{M})$, high $(\mathrm{H})$ and very high $(\mathrm{VH})$. In most cases, the Uniaxial compressive strength of the rock mass reaches $200 \mathrm{MPa}$ and rarely exceeds $200 \mathrm{MPa}$. During the modelling process, the results indicated that if the uniaxial compressive strength of a rock is higher than 100, rock mass will almost always be stable; this is the underlying reason for limiting this variable to $150 \mathrm{MPa}$. Graphic representation of membership functions of this variable in the modelling process is shown in Figure 3.

${ }^{5}$ Parameters in Table 1 are displayed in the order in which they are entered in the fuzzy logic designer (MATLAB)

6 "GMF" stands for Gaussian membership function and "TMF" stands for Trapezoid membership function 


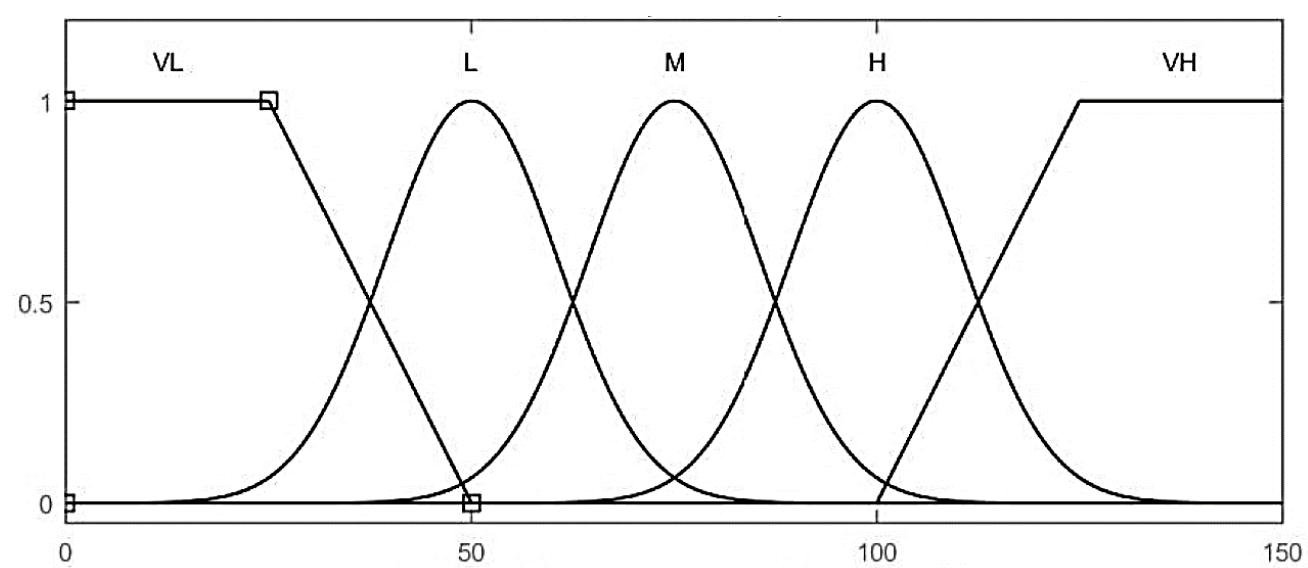

Figure 3 Membership functions of variable uniaxial compressive strength in the MATLAB fuzzy logic designer

\subsubsection{Object depth}

The object depth, expressed in meters, is classified into four groups with the linguistic determinants: very low (VL), low (L), medium (M), high (H) and very high (VH). The numerical values of this variable range from 0 to $1200 \mathrm{~m}$ given that the limits are related to Zaslavsky's field study on the classification of rock mass by stability [24]. In his experiment, he used depths ranging from $400 \mathrm{~m}$ to $1200 \mathrm{~m}$ while the model presented in this paper has been applied to underground facilities with depths lower than $400 \mathrm{~m}$. Zaslavsky's stability coefficient ranges from 0 to 0.65 , but according to Eq. 2 values for coefficient of stability, it can exceed 0.65 (another reason for limiting depth to $1200 \mathrm{~m}$ ). Figure 4. provides a graphical representation of membership functions for this type of input variable.

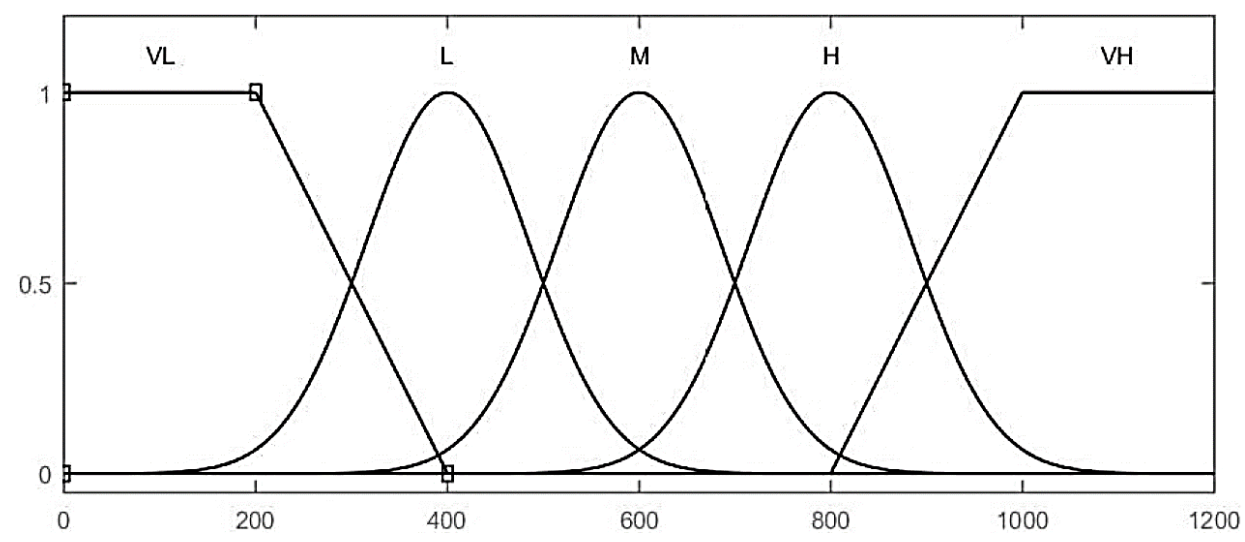

Figure 4 Membership functions of variable object depth in the MATLAB fuzzy logic designer 


\subsubsection{Unit weight of overburden}

The unit weight, expressed in $\mathrm{MN} / \mathrm{m}^{3}$, is divided into five groups with the linguistic variables: very low $(\mathrm{VL})$, low $(\mathrm{L})$, medium $(\mathrm{M})$, high $(\mathrm{H})$ and very high $(\mathrm{VH})$. For this input variable, and in order to define the numerical extents of each linguistic value of variable, table 2. and a classification provided by Jovanović (1990), were used. Figure 5 provides a graphic representation of this input variable with membership functions.

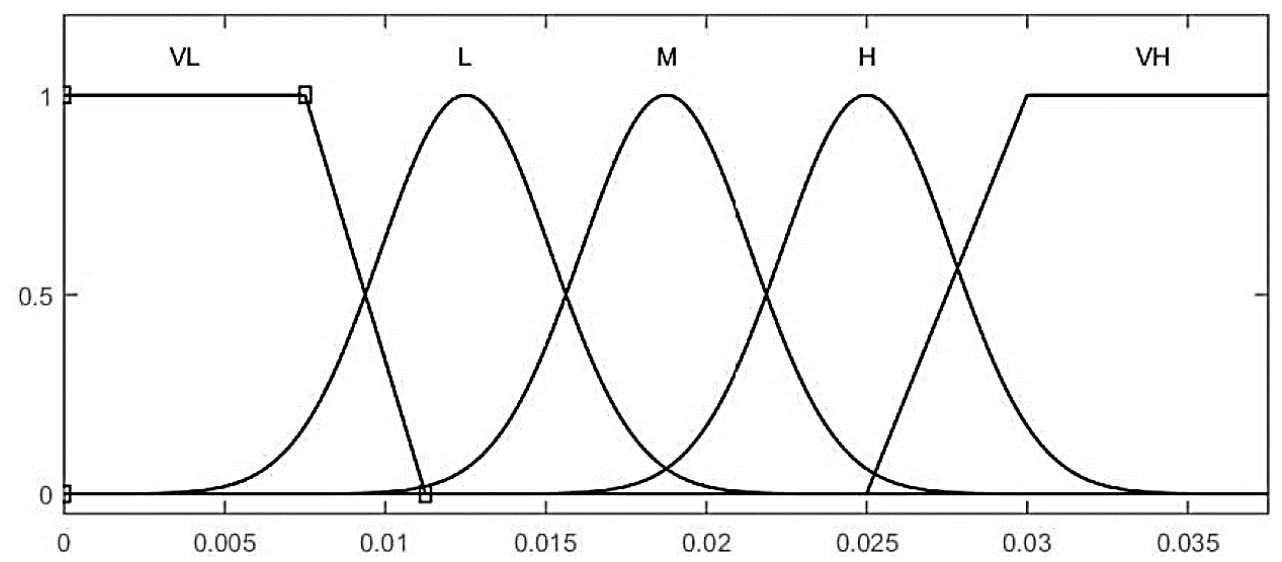

Figure 5 Membership functions of variable object depth in the MATLAB fuzzy logic designer

\subsubsection{Coefficient of stability}

The coefficient of stability is the only output variable and it is divided into three groups with linguistic determinants: high $(\mathrm{H})$, middle $(\mathrm{M})$, and low $(\mathrm{L})$. On the basis of the stability coefficient, Zaslavsky (Zaslavsky, 1979; Zaslavsky, 1966) proposed that a specific type of support system be used for those numeric values of coefficient of stability, taking into consideration the fall angle of the rock mass (i.e. as another type of input parameter). The dip angle can be divided into two groups (e.g. slightly sloping rock and steep rock) however classifying it without values in degrees has rendered Zaslavsky's classification incomplete. For this reason, this paper has rejected the angle of dip of rock mass as an influential factor. Zaslavsky's (Zaslavsky, 1966) classification proposal is shown in Table 2. 
Table 2 Classification of rock mass by stability

\begin{tabular}{cccc}
\hline $\begin{array}{c}\text { Stability } \\
\text { degree }\end{array}$ & \multicolumn{2}{c}{$\begin{array}{c}\text { Coefficient of stability, } \\
\text { depending on the dip angle of rock mass } \\
\text { Slightly sloping rock }\end{array}$} & $\begin{array}{c}\text { Type of support to be } \\
\text { used }\end{array}$ \\
\hline Stable rock & $0-0.25$ & $0-0.30$ & $\begin{array}{c}\text { Protective lightweight } \\
\text { support }\end{array}$ \\
$\begin{array}{c}\text { Medium stable } \\
\text { rock }\end{array}$ & $0.25-0.40$ & $0.30-0.45$ & $\begin{array}{c}\text { Incomplete frame } \\
\text { support }\end{array}$ \\
$\begin{array}{c}\text { Unstable rock } \\
\text { Sull frame support }\end{array}$ \\
\hline
\end{tabular}

Figure 6. provides a graphic representation of this input variable with membership functions.

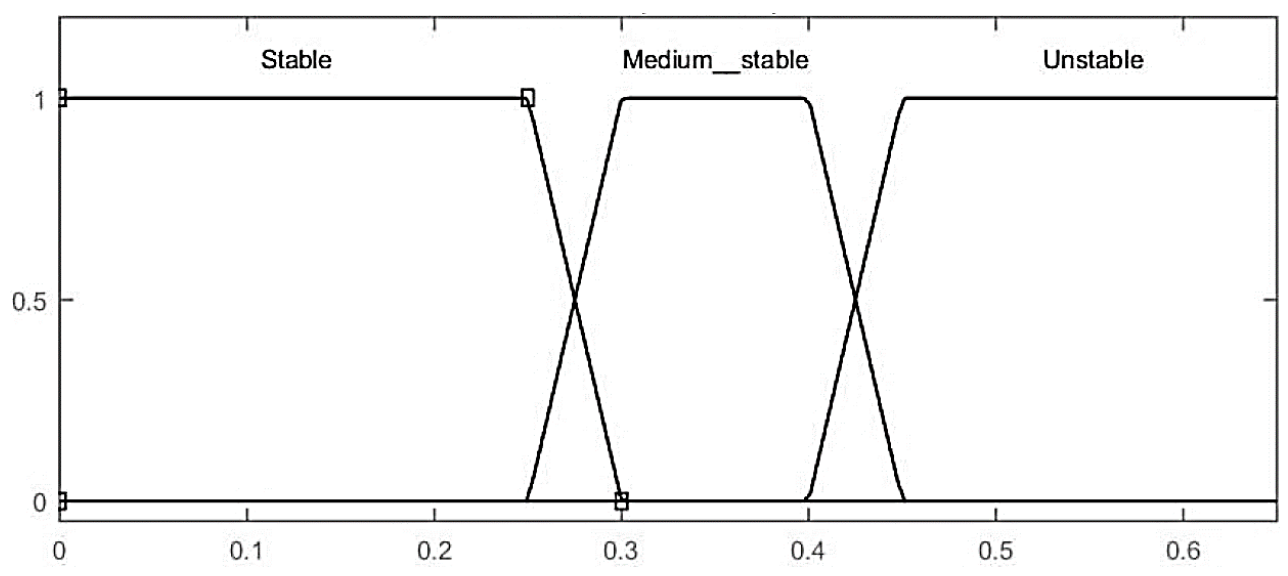

Figure 6 Output variable "Coefficient of stability" and its membership functions in the MATLAB fuzzy logic designer

The model consists of 125 "if-then" fuzzy rules. A comparative analysis between the model and Eq. 2, for ten randomly-chosen inputs of uniaxial compressive strength, object depth and unit weight, was made in order to determine the model's relevance. Randomlychosen input data (indicated in Table 3) was used for the verification of the model's validity. Some of rules are shown on figure 7. (a preview from rule editor) 
Table 3 Model input data

\begin{tabular}{cccc}
\hline Num. & $\begin{array}{c}\text { Uniaxial compressive strength } \\
(\mathrm{MPa})\end{array}$ & Object depth $(\mathrm{m})$ & Unit weight $\left(\mathrm{MN} / \mathrm{m}^{3}\right)$ \\
\hline 1 & 22 & 250 & 0.0150 \\
2 & 43 & 437 & 0.0266 \\
3 & 86 & 325 & 0.0297 \\
4 & 120 & 75 & 0.0230 \\
5 & 79 & 879 & 0.0294 \\
6 & 77 & 890 & 0.0335 \\
7 & 25 & 850 & 0.0233 \\
8 & 49 & 843 & 0.0270 \\
9 & 65 & 760 & 0.0244 \\
10 & 72 & 1130 & 0.0250 \\
\hline
\end{tabular}

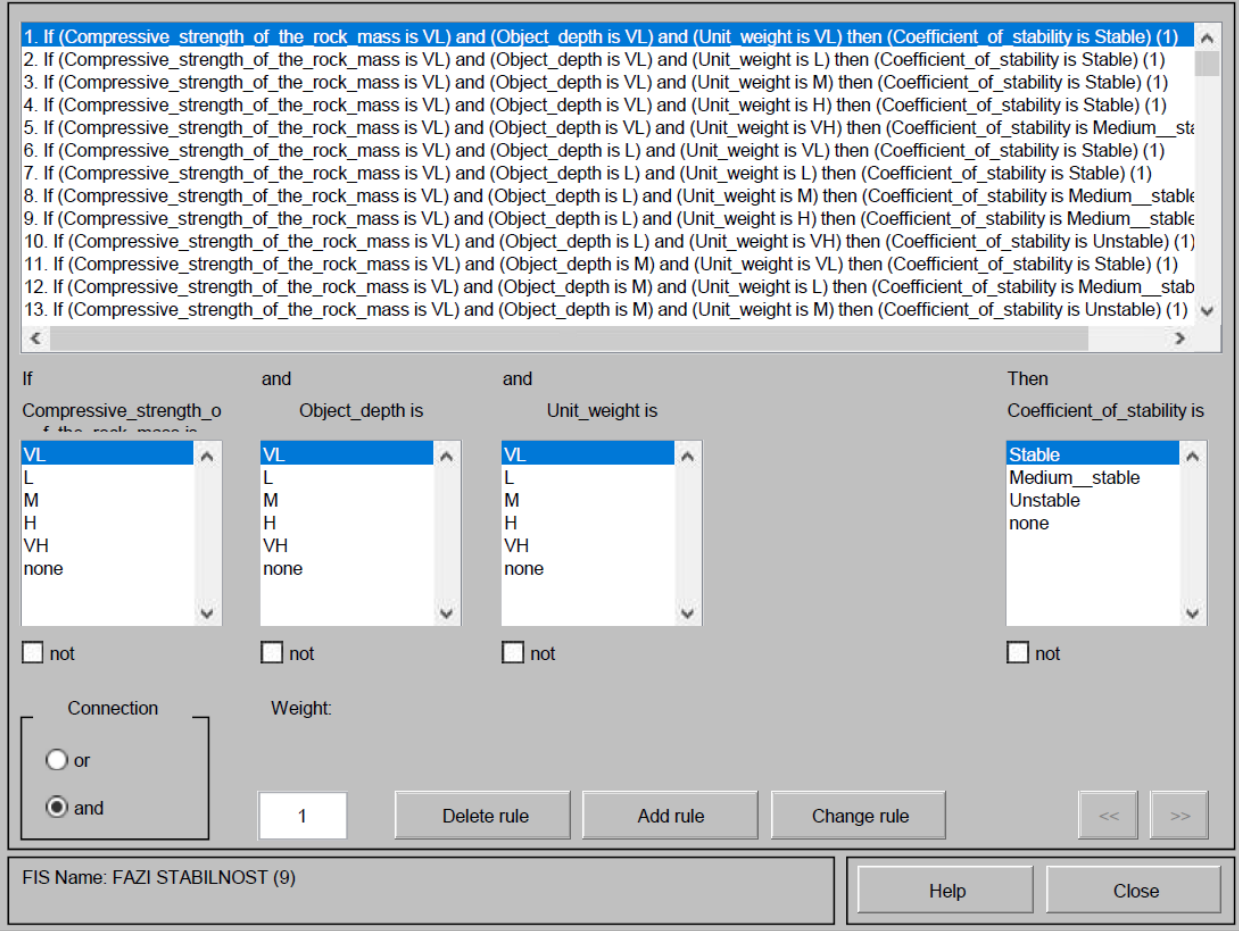

Figure 7 Fuzzy rule viewer with input data number 8 (from table 3) 


\section{RESULTS}

The comparative analysis for the values of the coefficient of stability (S) and the stability assessment for the data shown in Table 3 are presented in Table 4.

Table 4 Comparative analysis of results obtained by fuzzy model and equation (Eq. 2)

\begin{tabular}{ccccc}
\hline \multirow{2}{*}{ Number } & \multicolumn{2}{c}{ Fuzzy model calculation } & \multicolumn{2}{c}{ Calculation by equation (Eq. 2) } \\
& S value & Stability assessment & S value & Stability assessment \\
\hline 1 & 0.174 & Stable & 0.170 & Stable \\
2 & 0.243 & Stable & 0.270 & Stable - medium stability \\
3 & 0.142 & Stable & 0.112 & Stable \\
4 & 0.139 & Stable & 0.014 & Stable \\
5 & 0.386 & Medium stability & 0.327 & Medium stability \\
6 & 0.445 & Medium stability - instability & 0.387 & Medium stability \\
7 & 0.497 & Unstable & 0.792 & Unstable \\
8 & 0.425 & Medium stability - instability & 0.465 & Unstable \\
9 & 0.285 & Stable - medium stability & 0.285 & Stable - medium stability \\
10 & 0.367 & Medium stability & 0.392 & Medium stability \\
\hline
\end{tabular}

As shown in table 4, the results based on the fuzzy model have a high correlation rate with the stability assessment provided by Zaslavsky (Eq. 2) -therefore, the model could be used for the stability assessment of underground facilities in the early projection phase. As seen from table 4, numerical values for S, given by the fuzzy model (after defuzzification), and those calculated by Zaslavsky's equation (Eq. 2), are different in all 10 cases. However, according to the stability assessment of Zaslavsky's classification (Table 2), $70 \%$ of data (i.e. numbers 1,3,4,5,7,9 and 10 . from table 3 ) is classified in the same group -both in the model and by Zaslavsky's recommendation.

For the remaining $30 \%$, the stability assessment differs. In two particular cases, $\mathrm{S}$ has a lower value -when calculated by the model- and a higher stability assessment with example number 2 (table 3 ) being closer to the limit value between stable and medium stability (although classified as stable); while, according to Eq. 2, it would classify an underground facility with the same input variables as stable to medium stability. Example number 8 (table 3) also has a lower value of $\mathrm{S}$ and can be classified as medium stability to unstable while Eq. 2 is classified as unstable. Example number 6 (table 3) S value is higher than the one obtained by Eq. 2 -when calculated by the model- and gives the value of $\mathrm{S}$ close to unstable (although classified as medium stability to unstable); and by Eq. 2, that same underground facility would be classified as medium stability. Although there are few inconsistencies between the model and traditional stability assessment methods, the model can be applied to the preliminary adoption of shapes and dimensions of underground facilities. In reference to the value of stability, the variables must have linguistic values so that the engineer does not need to rely on the precise 
values of the rock mass characteristics. Only basic information is, therefore, needed in order to complete the task appropriately.

The relations between variables are shown on a 3D surface in Figure 8.(i.e. uniaxial compressive strength - unit weight of overburden), Figure 9.(i.e. uniaxial compressive strength - object depth) and figure 10.( i.e. unit weight of overburden - object depth).

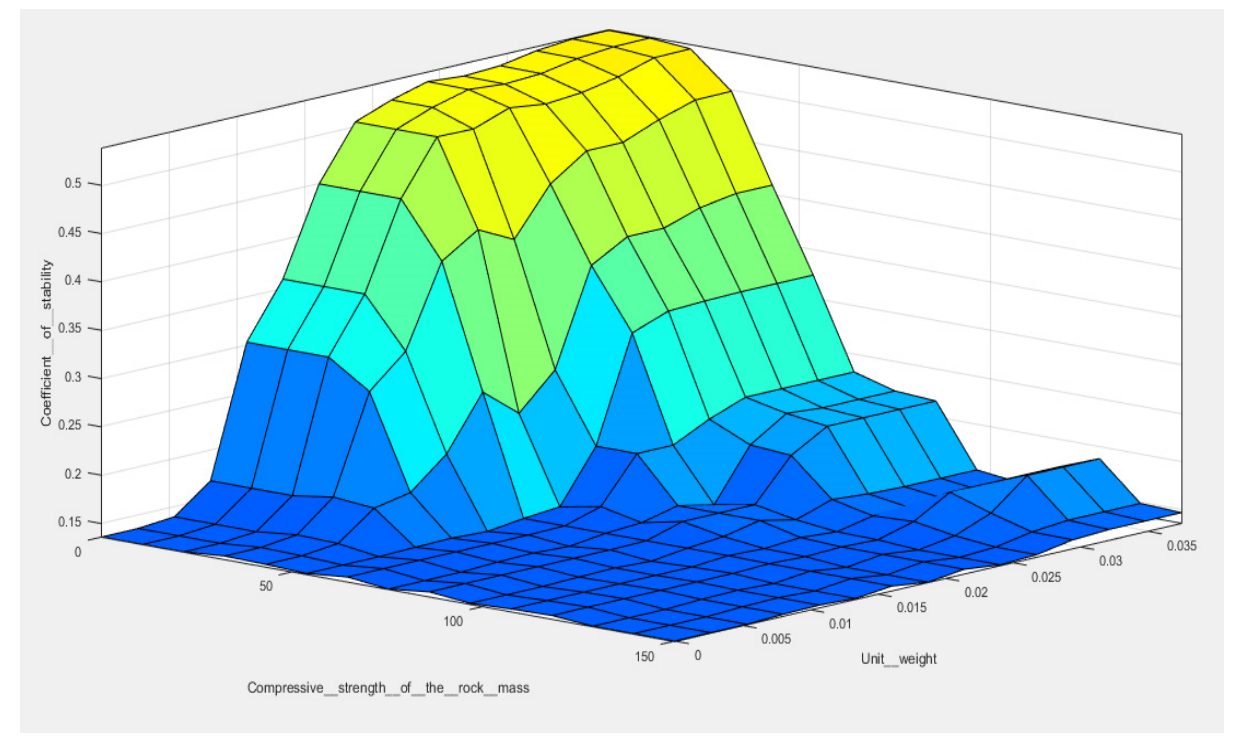

Figure 8 3D surface relations between variables uniaxial compressive strength, unit weight and coefficient of stability

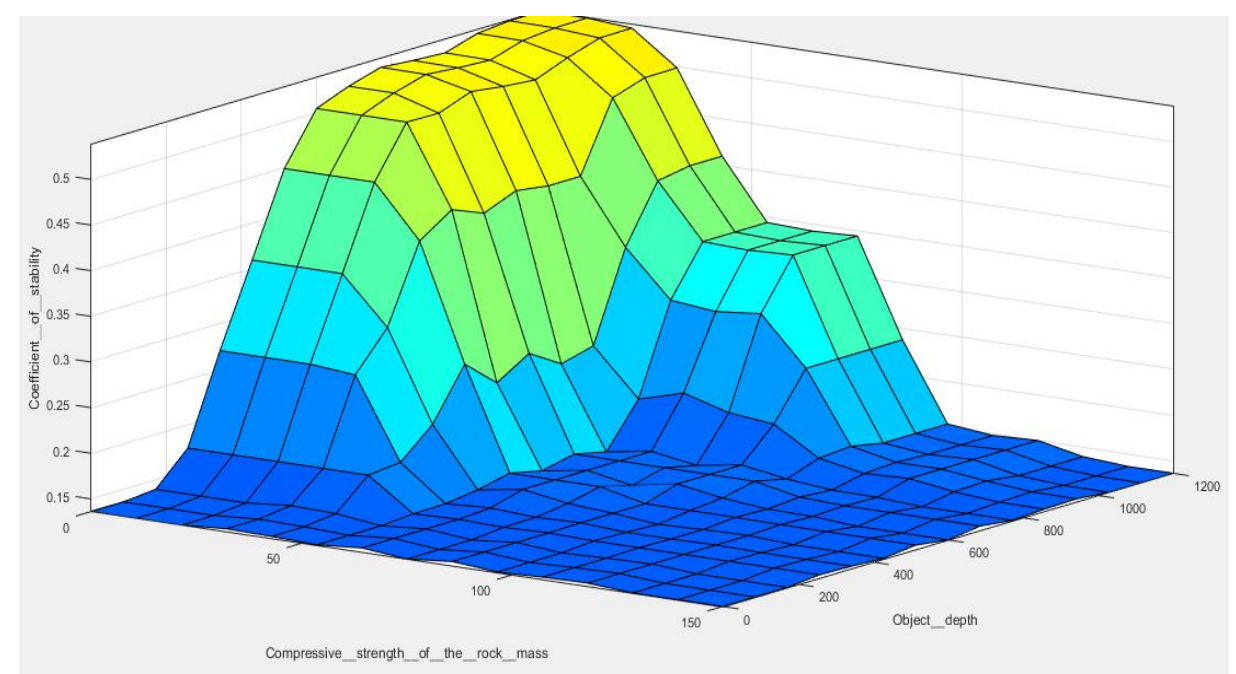

Figure 9 3D surface relations between variables uniaxial compressive strength, object depth and coefficient of stability 


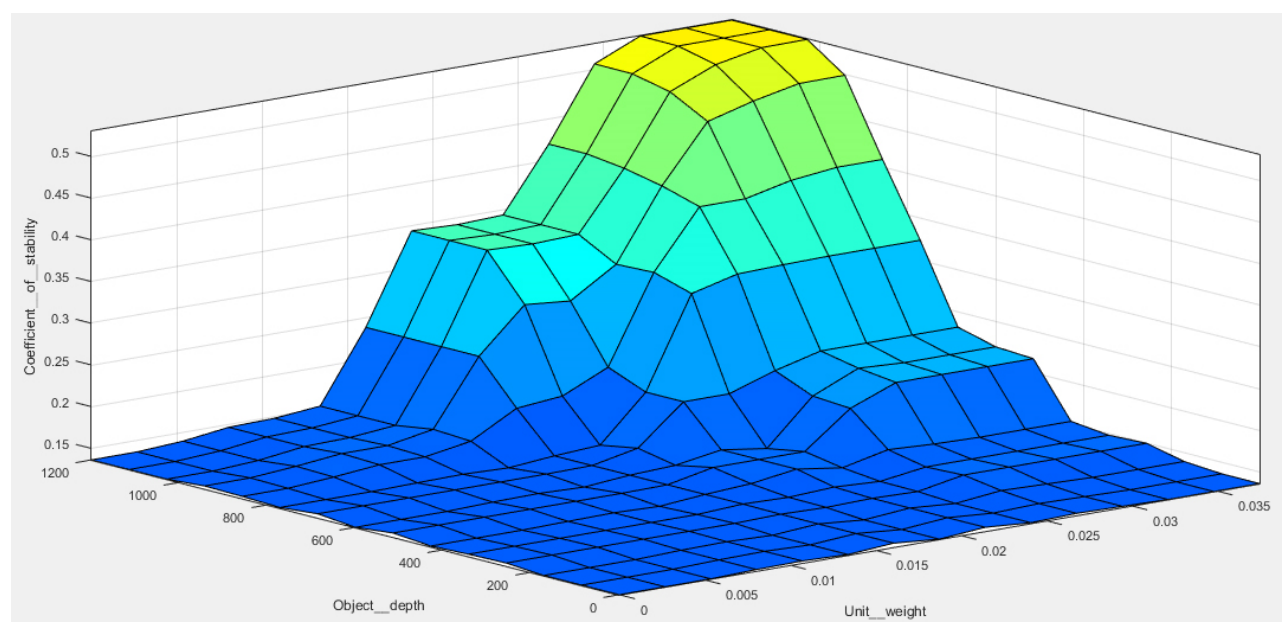

Figure 10 3D surface relations between variables object depth, unit weight and coefficient of stability

As seen from figures 8-10., the dependence on variables is displayed as well as their influence on coefficient of stability. The stability of underground facilities is ensured when the uniaxial compressive strength of rock mass has values higher than 100MPa or linguistic values ranging from "high" to "very high.;" For instance, underground roadways with working environments (those consisting of rocks with very high values of uniaxial compressive strength) will only need light protective support -i.e. with rock bolts. The stability of underground facilities drops in correlation with the uniaxial compressive strength value, given that the values of this variable range between $50 \mathrm{MPa}$ and $100 \mathrm{MPa}$ (or linguistically described as "medium" stability"). Furthermore, installation of the incomplete support frames is necessary to facilitate stability. Depending of the value of unit weight, depth of the underground facility, value and direction of underground pressure, as well as other factors, frames can then be created using either wood or steel. With values of uniaxial compressive strength less than $50 \mathrm{MPa}$, in combination with other factors, there is a higher probability that full frame support installation will be made from steel or even concrete (or reinforced concrete). Stability of underground facilities depends highly on the values of unit weight of the overburden, with unit weight values higher than $0.01 \mathrm{MN} / \mathrm{m}^{3}$, while values lower than that are hardly realistic; depending on the value of other variables (e.g. uniaxial compressive strength and object depth), stability changes drastically (as seen from figures 8 . and 10). Object depth, for values up to 200 to $300 \mathrm{~m}$, has a very small influence on higher depths than those depending on other factors -i.e. unit weight and uniaxial compressive strength stability change more drastically. 


\section{CONCLUSION}

The research in this paper has indicated that the fuzzy logic approach to the stability assessment of underground facilities is possible. Furthermore, results have shown, through the random selection of input data in the model, that in $70 \%$ of cases, there is high numerical congruence with the traditional, experimental- based method for determination of coefficient of stability S; and in $90 \%$ of cases, there is also congruence in accordance with the traditional approach to the classification of underground facilities based on the stability assessment. In the future, it is suggested that the fuzzy model be expanded with more input variables (i.e.: tectonic relations in rock mass, expected water inflow, etc.), as well as expanded in terms of object depth (values higher than 1200m) which would require additional field studies to be conducted. This model can also be used as one of the sub-models for defining the adequate support system, choice of shape and dimensions of the cross-section of underground facilities, which is particularly important in the early design phase where there is insufficient quality data on the characteristics of the rock mass. Model as well can be the starting point for developing the model for the fuzzy logic management process in underground construction.

\section{Acknowledgments}

This paper resulted from the Project No. 33029 financed by the Ministry of Education of the Republic of Serbia realized by the Faculty of Mining and Geology in Belgrade.

\section{REFERENCES}

LUTOVAC, S. et al.. (2018) Models of Determining the Parameters of Rock Mass Oscillation Equation with Experimental and Mass Blasting. Minerals, 2018, 8, 70. DOI : https://www.mdpi.com/2075-163X/8/2/70

KOBLIŠKA, M. A. (1973) Opšti rudarski radovi [General mining operations], 2nd ed., Građevinska knjiga: Belgrade, Serbia

JOVANOVIĆ, P. (1990) Izrada jamskih prostorija [Construction of underground facilities], 1st ed., Faculty of Mining and Geology: Belgrade, Serbia

JOVANOVIĆ, P. and ZEKOVIĆ, M. (1992) Stabilnost podzemnih prostorija, uslovi i ocena. In: Stabilnost podzemnih prostorija [Stability of underground facilities], pp. 1929., Faculty of Mining and Geology: Belgrade, Serbia

JOVANOVIĆ, P. (1994) Projektovanje i proračun podgrade horizontalnih podzemnih prostorija - knjiga 1 [Design and calculation of support of horizontal underground facilities - book 1], Faculty of Mining and Geology: Belgrade, Serbia

VIDANOVIĆ, N. and TOKALIĆ, R. (2011) Praktikum iz izrade jamskih prostorija [Practicum in construction of underground facilities], Faculty of Mining and Geology: Belgrade, Serbia

MILISAVLJEVIĆ, V., et al. (2016) Modelling of AT Rockbolts Parameters for "Soko" Underground Coal Mine. Tehnički Vjesnik, Vol. 23 No. 3, 2016. DOI: 
https://hrcak.srce.hr/index.php?show=clanak\&id_clanak_jezik=236131\&lang=en [Accessed 15 May 2020]

ZADEH, L.A. (1965) Fuzzy sets. Information and control, Vol. 8, issue 3, pp. 338-353.

KRIČAK, L., Negovanović, M., Mitrović, S., Miljanović, I., Nurić, S. and Nurić, A. (2015) Development of a fuzzy model for predicting the penetration rate of tricone rotary blasthole drilling in open pit mines. Journal of the Southern African Institute of Mining and Metallurgy, 2015. 115(11), Johannesburg, South Africa, http://www.scielo.org za/scielo.php?script=sci arttext\&pid=S222562532015001100019 [Accessed 15 May 2020]

AYDIN, A. (2004) Fuzzy set approaches to classification of rock masses. Engineering Geology, 2004. 74, pp. 227-245. https://engineering.olemiss.edu/gge/research /files/pdf/Fuzzy_set_approaches_to_classification_of_rock_masses.pdf [Accessed 20 May 2020].

HAMIDI, J.K., et al. (2010) Application of Fuzzy Set Theory to Rock Engineering Classification Systems: An Illustration of the Rock Mass Excavatability Index. Rock Mechanics and Rock Engineering, 2010.43(3), pp. 335-350. https://link.springer.com/article/10.1007/s00603-009-0029-1, [Accessed 23 May 2020]

HE, H., et al. (2014) Study and Application on Stability Classification of Tunnel Surrounding Rock Based on Uncertainty Measure Theory. Mathematical Problems in Engineering, 2014. volume 2014, Article ID 626527, 5 pages. https://doi.org/10.1155/2014/626527

DAFTARIBESHELIA, A., ATAEI M. and SERESHKIB, F. (2011) Assessment of rock slope stability using the Fuzzy Slope Mass Rating (FSMR) system, Applied Soft Computing, 2011. 11(8) pp. 4465-4473, https://www.sciencedirect.com/science/ article/pii/S156849461100 3152, [Accessed 19 May 2020]

TRÉFOVÁ, L., LAZAROVÁ, E. and KRÚPA, V. (2011) Application of fuzzy methods in tunnelling, Acta Montanistica Slovaca 16(3), pp. 197-208, http://citeseerx.ist. psu.edu/viewdoc/download?doi=10.1.1.220.8815\&rep=rep1\&type=pdf, [Accessed 19 May 2020]

TOKALIĆ, R., VIDANOVIĆ, N. and SAVIĆ, Lj. (2013) The rational technology model selection of the underground drivage development for the given conditions. Podzemni radovi, 23 (2013), pp. 11-20. http://ume.rgf.bg.ac.rs/index.php/ume/article/view/47/40, [Accessed 19 May 2020]

MILJANOVIĆ, I. (2008) Fuzzy logic management of processes in mineral processing, Faculty of Mining and Geology: Belgrade, Serbia

VUJIĆ, S. and MILJANOVIĆ, I. (2013) Fazi logika u rudarstvu [Fuzzy logic in mining engineering], Akademija inženjerskih nauka Srbije and Rudarski institut d.o.o. Beograd: Belgrade, Serbia 
JOVANOVIĆ, S. et al. (2014) Fuzzy Model for Selection of Underground Mine Development System in a Bauxite Deposit. Arabian Journal for Science and Engineering, 2014, 39(6), pp. 4529-4539. DOI: 10.1007/s13369-014-1173-9

BAJIĆ, S. et al. (2020) Application of Fuzzy Analytic Hierarchy Process to Underground Mining Method Selection. Symmetry 2020, 12 (2), 192, DOI: doi.org/10.3390/sym12020192

JANG, J. R., SUN, C. and MIZUTANI, E. (1997) Neuro-Fuzzy and Soft computing, Practice Hall, Upper Saddle River, New Jersey

MAMDANI, E.H. and ASSILIAN, S. (1975) An experiment in linguistic synthesis with a fuzzy logic controller. International Journal of Man-Machine Studies, 1975. 7(1), pp. $1-13$.

ZASLAVSKY, Ju. Z. (1979) Mostikov, V. M.; Крепление подземных сооружений, [Construction of underground facilities]. Nedra: Moscow, Soviet Union

ZASLAVSKY, Ju. Z. (1966) Исследование проявления горного давления в капитальных выработках глубоких шахт Донбасса [Investigation of rock pressure manifestations in capital roadways of deep mines of Donbas]. Nedra: Moscow, Soviet Union 